\title{
Explaining the 25-year decline of serum cholesterol by dietary changes and use of lipid-lowering medication in Finland
}

\author{
Liisa M Valsta*, Heli Tapanainen, Jouko Sundvall, Tiina Laatikainen, Satu Männistö, \\ Pirjo Pietinen and Erkki Vartiainen \\ National Institute for Health and Welfare, PO Box 30, Fl-00271, Helsinki, Finland
}

Submitted 20 July 2009: Accepted 15 March 2010

\begin{abstract}
Objective: To assess to what extent the observed dietary changes and increased use of lipid-lowering medication can explain the almost $20 \%$ decline in serum cholesterol (referring to serum total cholesterol) level observed from 1982 to 2007 in Finland.

Design: Predicted changes of serum cholesterol were calculated by the Keys' equation assuming the effect of trans fatty acids to be similar to SFA and using the dietary intake data of the national dietary surveys between 1982 and 2007. The effect of medication was estimated based on the information on use of lipid-lowering medication among survey participants. The predicted serum cholesterol levels were compared with observed changes in analysed serum cholesterol levels.

Setting: Four cross-sectional population surveys, in 1982, 1992, 2002 and 2007, in the provinces of North Karelia, Northern Savo and Southwestern Finland.

Subjects: A total of 2325 men and 2638 women aged 26-64 years selected randomly from the national population register for the four surveys.

Results: Changes in dietary fat quality and cholesterol intake explain $0.70 \mathrm{mmol} / \mathrm{l}$ (65\%) of the decrease in men and $0.65 \mathrm{mmol} / \mathrm{l}(60 \%)$ of the decrease in women in all subjects. Decline in dietary SFA intake is the main explanatory factor ( $47 \%$ in men and $41 \%$ in women) for the changes. The impact of lipid-lowering medication on observed cholesterol levels was found to be $16 \%$ among men and $7 \%$ among women.

Conclusions: The decrease in serum cholesterol levels in Finland can be explained mainly by dietary changes, especially changes in fat quality. The effect of lipidlowering medication is less significant.
\end{abstract}

In Finland, mortality rates for middle-aged men from CVD were the highest in the world in the late $1960 \mathrm{~s}^{(1)}$. The main objectives of pilot programmes like the North Karelia Project ${ }^{(1)}$ and of national policies have been to reduce the extremely high-risk factor levels, blood pressure, smoking and serum cholesterol. At that time, serum total cholesterol was the feasible serum cholesterol marker to be monitored in population studies. In this study serum cholesterol refers to serum total cholesterol.

The Finnish diet has traditionally been high in SFA and low in PUFA. The intake of dietary cholesterol was also markedly high some decades ago. There have been major changes in the Finnish diet during the past 25 years. Consumption of major sources of SFA, such as high-fat milk products and butter fat as butter and in buttervegetable oil mixtures have decreased considerably, by $86 \%$ and $67 \%$ respectively. Conversely, at the same time the consumption of low-fat milk products $(\leq 2.5 \%$ of fat during this period) has increased by $16 \%$ and, more importantly, the fat content of low-fat liquid milks has decreased on average from $\sim 2.5 \%$ to $\sim 1 \%$. The consumption of skimmed milk has increased six-fold during this period, from $8 \mathrm{~kg} /$ year to $\sim 48 \mathrm{~kg} /$ year $^{(2,3)}$. The total consumption of vegetable oil-containing margarines has not changed considerably, but the fatty acid profile has changed towards a higher proportion of unsaturated fatty acids. Furthermore, since the early 1980s the annual consumption of vegetables has almost tripled and that of fruit and berries increased by $\sim 20 \%$.

The use of lipid-lowering medication, and especially the use of more effective drugs like statins, has increased continuously in Finland $^{(4)}$. While in the early 1980s the use of lipid-lowering medication was very low and statins were not yet in use, $\sim 10 \%$ of the population aged $25-74$ years reported to using statins in $2007^{(5)}$. The use of medication is, however, naturally higher among older age groups, where it exceeds $30 \%$, compared to only a few percentage among younger adults.

The aim of this study is to assess to what extent the observed dietary changes and increased use of statins can 
explain the almost $20 \%$ decline in serum cholesterol level observed from 1982 to 2007.

\section{Subjects and methods}

Four cross-sectional population surveys, in 1982, 1992, 2002 and 2007, assessed the levels of several CHD risk factors and health-related parameters, including serum cholesterol and the use of cholesterol-lowering medication, in the provinces of North Karelia, Northen Savo (Kuopio) and Southwestern Finland (Turku-Loimaa). For each survey, a stratified random sample for each area was drawn from the national population register. The samples were stratified by sex and 10-year age group. The age range for the data used in the present study was 25-64 years (Tables 1 and 2).

\section{Dietary intake}

The dietary intakes have been monitored in the FINDIET surveys that have included randomly $\sim 30 \%$ of those participants invited to take part in the National FINRISK studies. Food consumption data were collected using estimated $3 \mathrm{~d}$ food records in $1982^{(6)}$ and in $1992^{(7)}$. In the FINDIET 2002 and 2007 surveys, the food consumption data were collected using a computer-assisted $48 \mathrm{~h}$ dietary recall method to ensure as high a participation rate as possible ${ }^{(8,9)}$. Portion size estimation was carried out in 1982 using household measures and known portion sizes, and since 1992, using a validated picture booklet ${ }^{(10)}$, which was expanded and validated for the 2002 and 2007 surveys ${ }^{(11)}$. The participation rates in the surveys included in the present study have ranged from 60\% to 66\%.

Dietary intakes were calculated in 1982 by an in-house dietary intake calculation software and food composition database of the Department of Nutrition, University of Helsinki; in 1992 with the in-house developed Setti-N calculation software and food composition database; and, since 2002, with the Finessi calculation software and the national food composition database Fineli ${ }^{\circledR(6-9)}$ (National Institute for Health and Welfare, Helsinki, Finland).

The Fineli ${ }^{\circledR}$ dietary cholesterol database was updated with new values for the 2002 dietary survey. In this analysis, average dietary cholesterol intake for 2002 and 2007 was increased by $19 \%$ in the updated database to account for an estimated measurement error due to a systematic change in analysed values caused by changes in laboratory methods of measuring dietary cholesterol ${ }^{(12)}$.

Predicted changes of serum cholesterol were calculated by the Keys' equation ${ }^{(13)}$ :

$$
\Delta \mathrm{S}-\mathrm{Chol}(\mathrm{mg} / \mathrm{dl})=2.7 \times \Delta \mathrm{SFA}-1.3 \times \Delta \mathrm{PUFA}+1.5 \Delta Z
$$

where SFA ad PUFA are percentages of total energy provided by saturated and polyunsaturated fatty acids, respectively, and $Z^{2}$ is expressed as $\mathrm{mg}$ dietary cholesterol $/ 4184 \mathrm{~kJ}(1000 \mathrm{kcal})$. The result of the equation was finally divided by 38.664 to convert to $\mathrm{mmol} / \mathrm{l}$. The effect

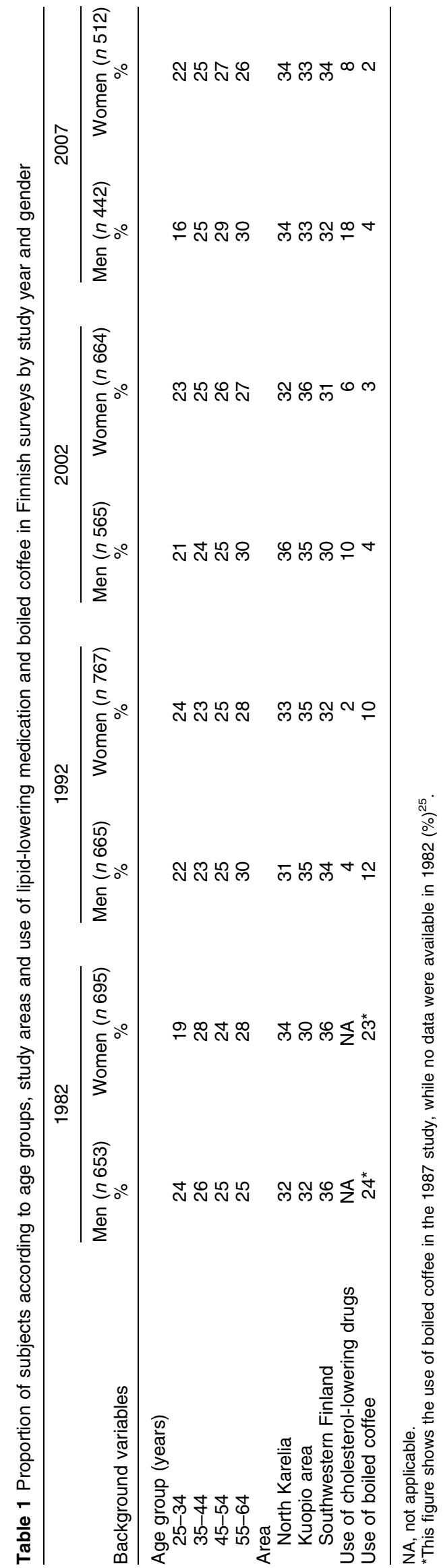


of trans fatty acids (TFA) was also taken into account in the calculations by assuming the effect of TFA on total cholesterol levels to be similar to SFA, as shown by a recent meta-analysis of thirteen dietary interventions ${ }^{(14)}$.

The effect of cholesterol-lowering drugs was taken into account in two different ways. First, the users of cholesterol lowering drugs were excluded before running the analyses. Second, we estimated the effect of cholesterollowering drugs to be $25 \%$ for the drug users and thus calculated the total medication effect. A question concerning the use of cholesterol-lowering drugs has been included in the study questionnaire since 1992. The data were age-standardized by study year to the Finnish population in 2001 for the analyses.

Analyses were also performed excluding energy underreporters, but the results did not change considerably. Under-reporters were defined by the Goldberg cut-off for energy intake, where energy intake was less than calculated basal metabolic rate. The cut-off points were 1.04 for 3 d estimated food records in the years 1982 and 1992 and $1 \cdot 0$ for the $48 \mathrm{~h}$ recalls in the years 2002 and $2007^{(15)}$.

\section{Laboratory analyses}

In the National FINRISK studies the total cholesterol analyses have been carried out between 1982 and 2002 from fresh serum samples and in 2007 from frozen serum samples in the same laboratory at the National Institute for Health and Welfare. The history of changes and systematic errors during decades for the cholesterol methods were described previously until $2002^{(16)}$. In 2007, total cholesterol was measured enzymatically (Abbott Laboratories, Abbott Park, IL, USA) using Architect c8000 analyzer (Abbott Laboratories). According to the Lipid Standardization Program organized by CDC (Atlanta, GA, USA), the systematic error (bias; mean and $\mathrm{SD}$ ) was $1.0 \%$ (SD 0.5 ) for cholesterol during the course of the FINRISK study comprising 4 months in 2007. The bias has been within the $\pm 3 \%$ bias limits during the FINRISK population survey between 1982 and $2007^{(16)}$.

\section{Lipid-lowering therapies}

The effects of different lipid-lowering therapies vary quite remarkably. In contrast, the treatment effects received by statins are reasonably constant, varying between $20 \%$ and $40 \%$ reduction in total cholesterol ${ }^{(17)}$. However, these results are from clinical trials in which the compliance rate with treatment is usually better than in the general patient population $^{(18)}$. Thus, in these analyses, a $25 \%$ reduction of total cholesterol was assumed among participants reporting using lipid-lowering medication.

\section{Results}

The subjects were reasonably evenly distributed into 10-year age groups, with the group of subjects aged 55-64 years 
old tending to be slightly larger than that of those aged 25-34 years old. This was most clear among men in the 2007 survey with $16 \%$ belonging to the youngest age group and $30 \%$ to the oldest age group. All study areas were represented by over $30 \%$ of the subjects. The main characteristics of the population of the present study are presented in the Table 1.

During the past 25 years the percentage of energy (E\%) from SFA intake has decreased from 18 to 13 among men and to 12 among women. At the same time the intake of PUFA has increased from $4.3 \mathrm{E} \%$ to $5.9 \mathrm{E} \%$ among men and to $5 \cdot 6 \mathrm{E} \%$ among women. The TFA intake has decreased on average from $\sim 1.5 \mathrm{E} \%$ to $0.4 \mathrm{E} \%$. In the whole study sample, serum cholesterol levels were on average $6 \cdot 1 \mathrm{mmol} / 1$ in 1982 and had decreased to $5 \cdot 3 \mathrm{mmol} / \mathrm{l}$ among men and to $5 \cdot 1 \mathrm{mmol} / \mathrm{l}$ among women by the year 2007 (Table 2 ).

Serum cholesterol levels have decreased by $0.76 \mathrm{mmol} / 1$ in men and by $0.92 \mathrm{mmol} / \mathrm{l}$ in women not using lipidlowering medication. Total dietary effect (estimated by the Keys' equation + TFA change) accounts for a $-0.55 \mathrm{mmol} / \mathrm{l}$ decline in serum cholesterol (72\%) among men and $-0.58 \mathrm{mmol} / 1(63 \%)$ among women. Intake of SFA is the main contributor, explaining $47 \%$ of serum cholesterol decline in men and $41 \%$ in women. The share of TFA of the total dietary effect is, according to this estimate, $13 \%$ among men and 14\% among women. Dietary cholesterol accounts only for $9 \%$ of the change in both genders. About half of the changes, and in the case of TFA over two-thirds of them, occurred during the first 10 years after 1982 (Table 3, Fig. 1).

When all subjects, including those using lipid-lowering medication, are considered, serum cholesterol decline has been $0.86 \mathrm{mmol} / \mathrm{l}$ in men and $0.97 \mathrm{mmol} / \mathrm{l}$ in women during the past 25 years (Table 4, Fig. 2). The joint effect of dietary factors and medication is estimated to account for $-0.70 \mathrm{mmol} / \mathrm{l}(81 \%)$ in men and $-0.65 \mathrm{mmol} / 1$ (67\%) in women. Changes in dietary fats and cholesterol intake alone explain $65 \%$ of the change in men and $60 \%$ of the change in women among this group. The impact of cholesterol-lowering medication was found to be $16 \%$ among men and $7 \%$ among women (Table 4, Fig. 2).

\section{Discussion}

The present study, carried out using large population surveys taken place during the past 25 years in Finland, is an example of the powerful effects that lifestyle changes, especially changes in fat quality, can have in serum cholesterol lowering at population level. The effect of cholesterollowering medication was shown to be clearly less significant.

The present study serves as an example of the value of a long history of collecting dietary and risk factor monitoring data that enable estimations of the kind shown in the present study. In Finland, similar estimations have been possible in the area of observed and predicted

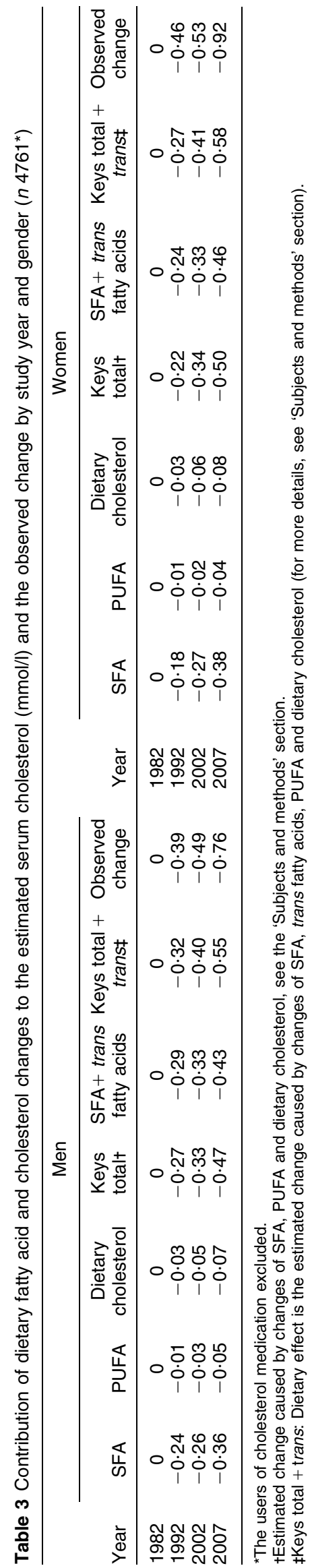


declines in mortality from ischaemic heart disease taking into account the major risk factors such as serum total cholesterol, blood pressure and smoking ${ }^{(19)}$ as well as the contribution of effective interventions such as cardiac surgery and medication ${ }^{(20)}$. These studies have shown how the remarkable decreases achieved in the population cholesterol level in Finland have decreased the risk of CHD and mortality. However, although the impact of diet as the main contributor to the observed serum cholesterol decline is evident and established, it had not been possible in these earlier analyses to estimate the real contribution of dietary and treatment changes. The present study is the first to systematically screen for the effects of diet and lipid-lowering medication on serum cholesterol levels in the Finnish population.

The effect of medication on the decline in serum cholesterol at the population level has been reasonably low, at only $0 \cdot 1 \mathrm{mmol} / 1$ since 1982 . However, the use of statins

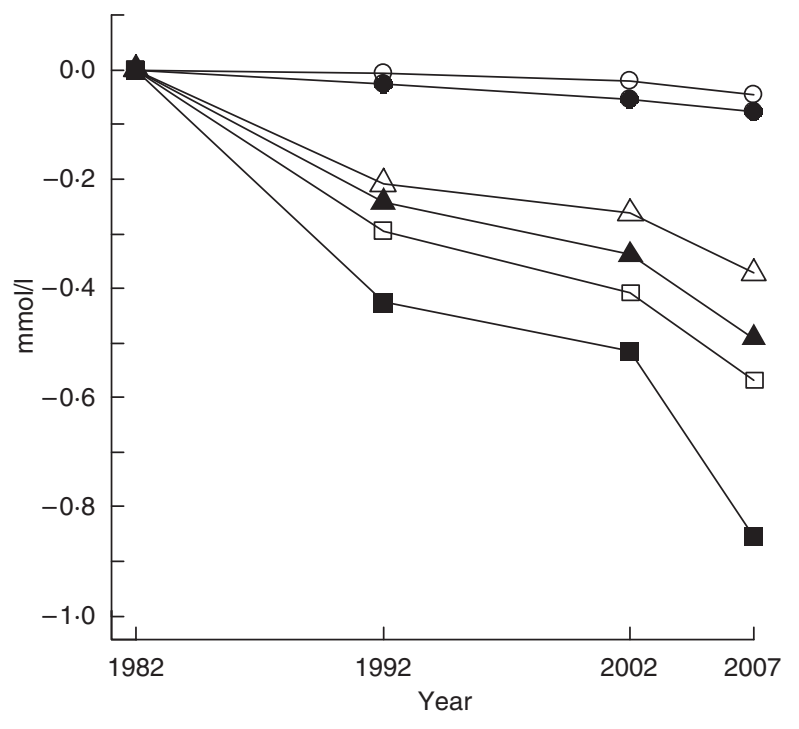

Fig. 1 Observed and predicted decline in serum cholesterol based on dietary changes in all subjects without lipid-lowering medication ( $n$ 4761; $\bigcirc$, PUFA; $\bullet$, dietary cholesterol; $\triangle$, SFA; $\boldsymbol{\Lambda}$, PUFA + dietary cholesterol + SFA; $\square$, PUFA + dietary cholesterol + SFA + trans fatty acids; $\mathbf{\square}$, observed serum cholesterol) among the population aged 25-64 years is still quite modest, particularly among women, although their use has increased at a remarkable pace, especially during the past 15 years. In addition to treatment rates, the effectiveness of the treatment of high cholesterol among women seems to be lower than among men in Finland ${ }^{(21)}$.

The contributions of fatty acids and dietary cholesterol on the change of serum total cholesterol were taken into account using the well-established serum cholesterol changes-predicting equation by Keys et $a l^{(13)}$. In that era, trans fatty acids were not separated in the metabolic studies from MUFA. Since the increasing body of evidence suggests that the effects of trans fatty acids are increasing serum cholesterol levels ${ }^{(22)}$, it was decided in the present study to add the effect of TFA into the analysis. This resulted in an additional estimated decline in serum cholesterol of $0.07-0.08 \mathrm{mmol} / 1$ in men and women, but did not totally explain the gap between the predicted and observed serum cholesterol values. The TFA intakes were not measured in the early 1980s and were therefore estimated from other types of data, referring to values

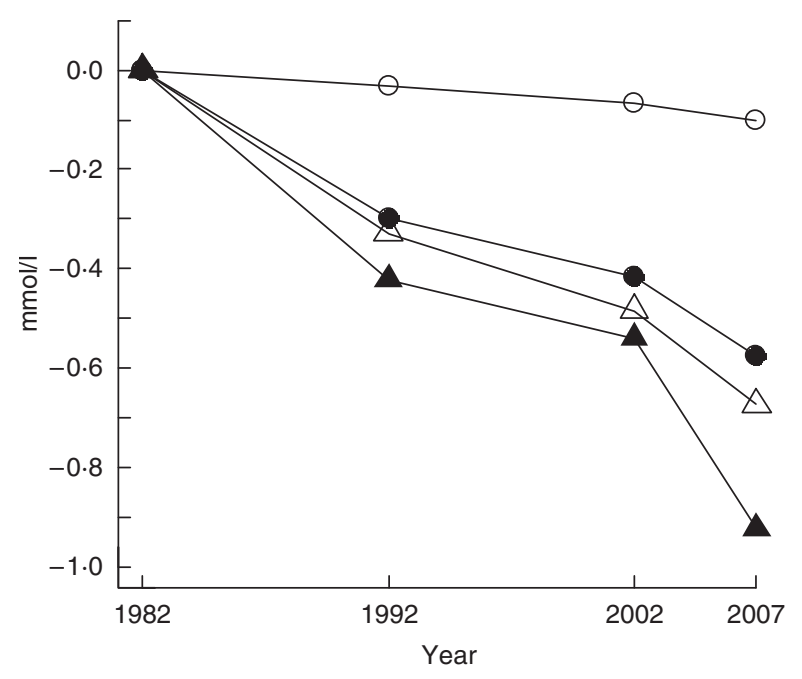

Fig. 2 Observed and predicted decline in serum cholesterol based on use of lipid-lowering medication and dietary changes in all subjects ( $n$ 4963; $\bigcirc$, medication effect; - , dietary effect; $\triangle$, medication + dietary effect; $\boldsymbol{\Lambda}$, observed serum cholesterol)

Table 4 Contribution of lipid-lowering medication and dietary effect to the estimated serum cholesterol (mmol/l) and the observed change by study year and gender ( $n$ 4963)

\begin{tabular}{|c|c|c|c|c|c|c|c|c|c|}
\hline & \multicolumn{4}{|c|}{ Men } & & \multicolumn{4}{|c|}{ Women } \\
\hline & $\begin{array}{l}\text { Medication } \\
\text { effect }\end{array}$ & $\begin{array}{l}\text { Dietary } \\
\text { effect }^{*}\end{array}$ & $\begin{array}{l}\text { Medication }+ \\
\text { dietary effect }\end{array}$ & $\begin{array}{l}\text { Observed serum } \\
\text { cholesterol difference }\end{array}$ & & $\begin{array}{l}\text { Medication } \\
\text { effect }\end{array}$ & $\begin{array}{l}\text { Dietary } \\
\text { effect }^{\star}\end{array}$ & $\begin{array}{l}\text { Medication }+ \\
\text { dietary effect }\end{array}$ & $\begin{array}{c}\text { Observed serum } \\
\text { cholesterol difference }\end{array}$ \\
\hline $\begin{array}{l}1982 \\
1992 \\
2002 \\
2007\end{array}$ & $\begin{array}{c}0 \\
-0.04 \\
-0.09 \\
-0.14\end{array}$ & $\begin{array}{c}0 \\
-0.32 \\
-0.42 \\
-0.56\end{array}$ & $\begin{array}{c}0 \\
-0.37 \\
-0.51 \\
-0.70\end{array}$ & $\begin{array}{c}0 \\
-0.37 \\
-0.51 \\
-0.86\end{array}$ & $\begin{array}{l}1982 \\
1992 \\
2002 \\
2007\end{array}$ & $\begin{array}{c}0 \\
-0.02 \\
-0.05 \\
-0.06\end{array}$ & $\begin{array}{c}0 \\
-0.27 \\
-0.41 \\
-0.58\end{array}$ & $\begin{array}{c}0 \\
-0.29 \\
-0.46 \\
-0.65\end{array}$ & $\begin{array}{c}0 \\
-0.46 \\
-0.56 \\
-0.97\end{array}$ \\
\hline
\end{tabular}

*Dietary effect: Keys total + trans is the estimated change caused by changes of SFA, trans fatty acids, PUFA and dietary cholesterol (for more details, see 'Subjects and methods' section). 
derived mainly from Germany ${ }^{(23)}$. This estimation of TFA intake to be roughly $1.5 \mathrm{E} \%$ in 1982 is thus somewhat uncertain. There is, however, no evidence showing that the intake of TFA would have been higher in Finland at that time even though there were higher intakes in some other European countries ${ }^{(24)}$. In some countries (The Netherlands, Norway) where margarine consumption was high and hydrogenated vegetable or fish oils were used, high intakes of TFA were found in the 1980s. In Finland, it is apparent that the changes between 1982 and 1992 in TFA intake reflected primarily, changes in milk fat intake, and thereafter mainly the effect of removing TFA from margarines in the mid-1990s. This is mainly because the TFA intake in the Finnish diet has, throughout these decades, been largely based on a high proportion of milk and beef fats.

Another dietary factor affecting the serum cholesterol levels has been shown to be the drinking of boiled coffee. It was shown that in 1987 the consumption of boiled coffee accounted for $0 \cdot 3-0.4 \mathrm{mmol} / \mathrm{l}$ of the serum cholesterol values in the late $1980 \mathrm{~s}^{(25)}$. There was no data available on the proportion of people drinking of boiled coffee in the 1982. However, in 1987, $24 \%$ of men and $23 \%$ of women drank boiled coffee, whereas in 1992 it was only $12 \%$ and $10 \%$, respectively. Since 1992 the proportion of boiled coffee consumers has further decreased from an average of $11 \%$ to $3 \%$ of the study population.

An increased intake of plant sterols inhibits the absorption of dietary cholesterol and hence lowers the serum cholesterol levels ${ }^{(26)}$. The main sources of plant sterols in the Finnish diet have been shown to be cereal products, vegetable-fat spreads and vegetable oils as well as vegetables themselves ${ }^{(12)}$. Although the consumption of cereal products have decreased, we have witnessed an increase in consumption of plant sterol-containing oils and fats, and a steep increase in the consumption of vegetables during the past decades ${ }^{(2)}$. With these developments the total plant sterol intake from natural foods, excluding consumption of special plant sterol/stanolenriched margarines, has been shown to have increased from $\sim 220-230 \mathrm{mg} / \mathrm{d}$ to $\sim 300 \mathrm{mg} / \mathrm{d}$ among Finnish men $^{(12,27)}$. It has been shown that $\sim 10 \%$ of that increase may be accounted for by methodological developments in the plant sterol analysis ${ }^{(12)}$. The increase of plant sterols from natural foods may have slightly affected the serum cholesterol levels throughout the duration of this analysis, but the effect may be small and does not explain a large part of the difference between the estimated and observed serum cholesterol levels. Since margarines enriched with plant sterols or stanols that have been on the market, i.e. since the 1990s, a 10-15\% decrease in serum cholesterol levels has been achieved ${ }^{(28)}$. The increased consumption of plant sterol- and stanol-containing margarines may have had an additional effect on the observed cholesterol levels during the past decade ${ }^{(29)}$. This effect would be mainly seen in the middle-aged and elderly subjects.
In the present study, the observed and predicted decline in serum cholesterol levels were closely similar throughout the time period among men, but diverged notably between 2002 and 2007 among women. One possible explanation for this gap could be the lengthened periods of use of hormone replacement therapies (HRT) in women ${ }^{(30)}$. In 1997, $28 \%$ of Finnish women used HRT and in 2007, it was $23 \%{ }^{(5)}$. As HRT has been shown mainly to decrease serum cholesterol levels, and discontinuing HRT to increase them ${ }^{(30)}$, the observed developments in treatment rates cannot explain the gap between the predicted and observed serum cholesterol levels found in our study.

In conclusion, the present study illustrates that the exceptionally large decrease in serum cholesterol levels in Finland over the past 25 years is mainly a result of dietary changes, especially changes in fat quality. The effect of lipid-lowering medication is less significant, especially in the working-age population.

\section{Acknowledgements}

The work of the National FINRISK study and FINDIET survey teams in collecting the data for the present study is gratefully acknowledged.

\section{References}

1. Puska P, Salonen JT, Nissinen A et al. (1983) Change in risk factors for coronary heart disease during 10 years of a community intervention programme (North Karelia Project). BMJ (Clin Res Ed) 287, 1840-1844.

2. Ministry of Agriculture and Forestry (2008) Balance sheet for food commodities. http://www.mmmtike.fi/en/index/ statistics_information_services/publications/balance_sheet_ food_commodities.html (accessed March 2010).

3. Männistö S, Laatikainen T, Helakorpi S et al. (2009) Monitoring diet and diet related chronic disease risk factors in Finland. Public Health Nutr (in this issue).

4. Social Insurance Institution of Finland (2009) Medicine costs and their reimbursement according to medicine group. Source: Prescription Register at the Social Insurance Institution of Finland. http://www.kela.fi/in/internet/liite. nsf/NET/270109123527PN/\$File/laakeryh.pdf?openElement (accessed March 2010).

5. Peltonen M, Harald K, Männistö S et al. (2008) Kansallinen FINRISKI 2007 - terveystutkimus (In Finnish, abstract and summary in English: The National FINRISK 2007 Study). Publications of the National Public Health Institute B34/2008. Helsinki: Yliopistopaino; available at http:// www.ktl.fi/attachments/suomi/julkaisut/julkaisusarja_b/2008/ 2008b34.pdf

6. Uusitalo U, Pietinen P \& Leino U (1987) Food and Nutrient Intake Among Adults in East and Southwest Finland - A Dietary Survey of the FIN-MONICA project in 1982. Publications of the National Public Health Institute B1/ 1987. Helsinki: Government Printing Centre.

7. Kleemola P, Virtanen M \& Pietinen P (1994) The 1992 Dietary Survey of Finnish adults. Publications of the National Public Health Institute B2/1994. Helsinki: Helsinki University Print. 
8. Männistö S, Ovaskainen ML \& Valsta L, (editors) (2003) Finravinto 2002-tutkimus (In Finnish, with summary in English: The National FINDIET 2002 Study). Publications of the National Public Health Institute B3/2003. Helsinki: Hakapaino Oy.

9. Paturi M, Tapanainen $\mathrm{H}$, Reinivuo $\mathrm{H}$ et al., (editors) (2008) The National FINDIET 2007 Survey (In Finnish, tables, figures and summary in English). Publications of the National Public Health Institute B23/2008. Helsinki: Yliopistopaino.

10. Pietinen P, Hartman AM, Haapa E et al. (1988) Reproducibility and validity of dietary assessment instruments. I. A self-administered food use questionnaire with a portion size picture booklet. Am J Epidemiol 128, 655-666.

11. Ovaskainen ML, Paturi M, Reinivuo H et al. (2008) Accuracy in the estimation of food servings against the portions in food photographs. Eur J Clin Nutr 62, 674-681.

12. Valsta LM, Lemström A, Ovaskainen ML et al. (2004) Estimation of plant sterol and cholesterol intake in Finland: quality of new values and their effect on intake. $\mathrm{Br} J \mathrm{Nutr}$ 92, 671-678.

13. Keys A, Anderson JT \& Grande F (1965) Serum cholesterol response to changes in the diet. IV. Particular saturated fatty acids in the diet. Metabolism 14, 776-787.

14. Mozaffarian D \& Clarke R (2009) Quantitative effects on cardiovascular risk factors and coronary heart disease risk of replacing partially hydrogenated vegetable oils with other fats and oils. Eur J Clin Nutr 63, S22-S33.

15. Goldberg GR, Black AE, Jebb SA et al. (1991) Critical evaluation of energy intake using fundamental principles of energy physiology: 1. Derivation of cut-off limits to identify under-recording. Eur J Clin Nutr 45, 569-581.

16. Sundvall J, Leiviskä J, Alfthan G et al. (2007) Serum cholesterol during 27 years: Assessment of systematic error and affecting factors and their role in interpreting population trends. Clin Chim Acta 378, 93-98.

17. Jones PH, Davidson MH, Stein EA et al. (2003) Comparison of the efficacy and safety of rosuvastatin versus atorvastatin, simvastatin and pravastatin across doses (STELLAR trial). Am J Cardiol 92, 152-160.

18. EUROASPIRE II Study Group (2001) Lifestyle and risk factor management and use of drug therapies in coronary patients from 15 countries; principal results from EUROASPIRE II Euro Heart Survey Programme. Eur Heart J 22, 554-572.

19. Vartiainen E, Puska P, Pekkanen J et al. (1994) Changes in risk factors explain changes in mortality from ischaemic heart disease in Finland. BMJ 309, 23-27.

20. Laatikainen T, Critchley J, Vartiainen E et al. (2005) Explaining the decline in coronary hear disease mortality in Finland between 1982 and 1997. Am J Epidemiol 162, 764-773.

21. Vartiainen E, Laatikainen T, Strandberg T et al. (2009) Kolesterolilääkkeiden käytössä on edelleen kohentamisen varaa. FINRISKI 2007-tutkimuksen tuloksia (In Finnish, summary in English: Use of cholesterol lowering drugs in FINRISK 2007). Suom Lääkäril 64, 4135-4139.

22. Mozaffarian D, Aro A \& Willett WC (2009) Health effects of trans-fatty acids: experimental and observational evidence. Eur J Clin Nutr 63, S5-S21.

23. Precht D \& Molkentin J (1995) Trans fatty acids: implications for health, analytical methods, incidence in edible fats and intake. Die Nabrung 39, 343-374.

24. Hulshof KFAM, van Erp-Baart MA \& Anttolainen M (1999) Intake of fatty acids in Western Europe with emphasis on trans fatty acids: The TRANSFAIR study. Eur J Clin Nutr 53, 143-157.

25. Pietinen P, Aro A, Tuomilehto J et al. (1990) Consumption of boiled coffee is correlated with serum cholesterol in Finland. Int J Epidemiol 19, 586-590.

26. Miettinen T \& Gylling H (1999) Regulation of cholesterol metabolism by dietary plant sterols. Curr Opin Lipidol 10, 9-14.

27. De Vries J, Jansen A, Kromhout D et al. (1997) The fatty acid and sterol content of food composites of middle-aged men in seven countries. J Food Compost Anal 10, 115-141.

28. Miettinen TA, Puska P, Gylling H et al. (1995) Reduction of serum cholesterol with sitostanol-ester margarine in a mildly hypercholesterolemic population. N EnglJ Med 333, 1308-1312.

29. Simojoki M, Luoto R, Uutela A et al. (2005) Use of plant stanol ester margarine among persons with and without cardiovascular disease: early phases of the adoption of a functional food in Finland. Nutr J 4, 20.

30. Pettee KK, Kriska AM, Conroy MB et al. (2007) Discontinuing hormone replacement therapy: attenuating the effect on CVD risk with lifestyle changes. Am J Prev Med 32, 483-489. 